\title{
Effect of hypothermia on interleukin-1 receptor antagonist pharmacodynamics in inflammatory-sensitized hypoxic-ischemic encephalopathy of term newborns
}

Mathilde Chevin, Clémence Guiraut and Guillaume Sébire*

\begin{abstract}
Background: Hypothermia is increasingly tested in several neurological conditions, such as neonatal encephalopathy, stroke, traumatic brain injury, subarachnoid hemorrhage, spinal cord injury, and neurological outcomes of cardiac arrest. Current studies aim to increase benefits of hypothermia with new add-on therapies including immunomodulatory agents. Hypothermia has been shown to affect the metabolism of commonly used drugs, including those acting on neuroimmune pathways.
\end{abstract}

Objective: This study focuses on the effect of hypothermia on interleukin-1 receptor antagonist pharmacodynamics in a model of neonatal encephalopathy.

Methods: The effect of hypothermia on (i) the tissue concentration of the interleukin-1 receptor antagonist, (ii) the interleukin-1 inflammatory cascade, and (iii) the neuroprotective potential of interleukin-1 receptor antagonist has been assessed on our rat model of neonatal encephalopathy resulting from inflammation induced by bacterial compound plus hypoxia-ischemia.

Results: Hypothermia reduced the surface of core and penumbra lesions, as well as alleviated the brain weight loss induced by LPS+HI exposure. Hypothermia compared to normothermia significantly increased (range 50-65\%) the concentration of the interleukin-1 receptor antagonist within the central nervous system. Despite this increase of intracerebral interleukin-1 receptor antagonist concentration, the intracerebral interleukin-1-induced tumor necrosis factor-alpha cascade was upregulated. In hypothermic condition, the known neuroprotective effect of interleukin-1 receptor antagonist was neutralized ( $50 \mathrm{mg} / \mathrm{kg} / 12 \mathrm{~h}$ for $72 \mathrm{~h}$ ) or even reversed (200 mg/kg/12 h for $72 \mathrm{~h}$ ) as compared to normothermic condition.

Conclusion: Hypothermia interferes with the pharmacodynamic parameters of the interleukin-1 receptor antagonist, through a bioaccumulation of the drug within the central nervous system and a paradoxical upregulation of the interleukin-1 pathway. These effects seem to be at the origin of the loss of efficiency or even toxicity of the interleukin-1 receptor antagonist when combined with hypothermia. Such bioaccumulation could happen similarly with the use of other drugs combined to hypothermia in a clinical context.

Keywords: Cerebral palsy, HT, IL-1Ra, Neonatal encephalopathy, Inflammation

\footnotetext{
* Correspondence: Guillaume.Sebire@mcgill.ca

Department of Pediatrics, McGill University, Research Institute of the McGill

University Health Centre, 1001 Decarie Boulevard, (Glen site, Block E,

M0.3211), Montreal, Quebec H4A 3J1, Canada
}

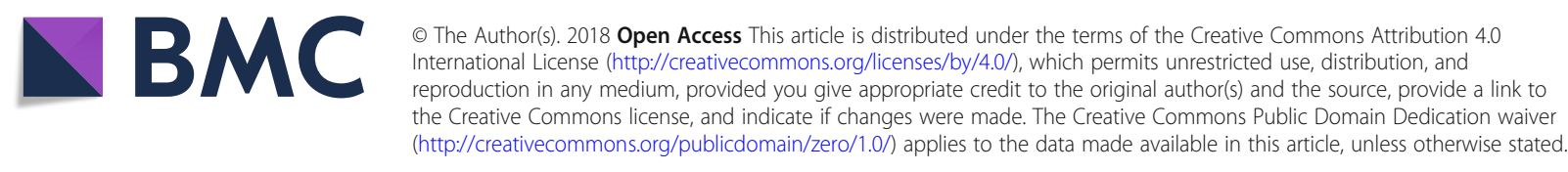




\section{Introduction}

Pure hypoxia-ischemia (HI) and inflammatory-sensitized $\mathrm{HI}$ are the most prevalent clinical scenarios underlying neonatal encephalopathy (NE) of term newborns, one of the leading causes of neonatal death or cerebral palsy [1]. Neuroprotective treatments available against NE of term newborns consist in symptomatic cares and hypothermia (HT) [2, 3]. Ongoing researches focus on new add-on therapies in combination to HT to increase its neuroprotective effect [2, 4]. However, recent evidence demonstrated that HT can alter the pharmacokinetic and pharmacodynamic parameters of drugs and induces unexpected and sometimes adverse effects [5-8]. Our team and others recently showed that HT fails to counteract the IL-1 system $[9,10]$, which plays a key role in NE [11-14]. Interleukin-1 receptor antagonist (IL-1Ra) has already demonstrated a protective perinatal efficacy on several organs, especially the brain, exposed to inflammation induced by bacterial compounds and/or HI [11, 12, 15, 16]. These results support a potential neuroprotective benefit of IL-1Ra as a targeted add-on therapy to HT. An initial step in evaluating the effect of IL-1Ra in combination with HT is to test the effect of HT on its pharmacodynamics in this physiopathological context. Our hypothesis is that HT modifies the pharmacodynamic parameters of IL-1Ra under perinatal inflammatory and/or HI conditions. Our objectives will test the effect of HT on (i) the tissue concentration of IL-1Ra, including the central nervous system; (ii) the inflammatory cascade of the IL-1 system; and (iii) the neuroprotective potential of IL-1Ra.

\section{Material and methods}

\section{Rat model}

Our preclinical model was designed as previously described $[9,14,15]$. Briefly, pups at postnatal day (P) 5-7 were obtained from Charles River Laboratories (Saint-Constant,
QC). At P12, they received a single intraperitoneal (ip) injection of lipopolysaccharide (LPS, $50 \mu \mathrm{g} / \mathrm{kg}$ diluted in $50 \mu \mathrm{l}$ of pyrogen-free saline) from Escherichia coli (Sigma-Aldrich, ON). HI was induced $4 \mathrm{~h}$ after LPS administration by permanent ligation of the right common carotid artery followed by $8 \% \mathrm{O}_{2}$ exposure at $36{ }^{\circ} \mathrm{C}$ for $1.5 \mathrm{~h}[9,15,17]$. HT was induced $30 \mathrm{~min}$ after hypoxia, as previously described [9]. Briefly, pups were kept on a hot plate at $32{ }^{\circ} \mathrm{C}$ in order to lower their core body temperature until $32.5{ }^{\circ} \mathrm{C} \pm 0.5{ }^{\circ} \mathrm{C}$ (Fig. 1). HT was maintained in a reproducible manner for $4 \mathrm{~h}$. LPS+HI and LPS $+\mathrm{HI}+\mathrm{IL}-1 \mathrm{Ra}$ pups stayed with the dam during the time their peers underwent HT [9].

Human recombinant (hr) IL-1Ra was used at a concentration of 50 or $200 \mathrm{mg} / \mathrm{kg}$ (diluted in $50 \mu \mathrm{l}$ of pyrogen-free saline). Both doses are commonly used in the perinatal preclinical context to protect the organs against inflammation and/or HI $[15,16]$. The first injection was given ip, $30 \mathrm{~min}$ before LPS injection. Five other injections were given every $12 \mathrm{~h}$ thereafter (Fig. 1). The end of hypoxia referred to as $0 \mathrm{~h}$. Pups were euthanized at $4 \mathrm{~h}$ (which correspond to the end of HT), $24 \mathrm{~h}$ (P13), or 8 days (P20) post-HI. A total of 181 pups were included in the study. Pups were randomized in five experimental groups, namely 35 pups in LPS+HI condition, 32 pups in $\mathrm{LPS}+\mathrm{HI}+\mathrm{HT}$ condition, 24 pups in LPS $+\mathrm{HI}+\mathrm{IL}-1 \mathrm{Ra}$ (50 $\mathrm{mg} / \mathrm{kg}$ ) condition, 52 pups in LPS+HI+HT+IL-1Ra (50 $\mathrm{mg} / \mathrm{kg})$, and 7 pups in LPS+HI+HT+IL-1Ra (200 mg/kg). Among all pups subjected to LPS $+\mathrm{HI} \pm \mathrm{HT}$ $\pm \operatorname{IL}-1 \mathrm{Ra}(n=181)$, the mortality rate was $17 \%$ (death occurred for all pups during hypoxia, except for 3 pups who died within $10 \mathrm{~h}$ following hypoxia). No significant difference was observed in the mortality rate between all experimental groups.

The experimental protocol was approved by the Institutional Animal Care Committee of the McGill

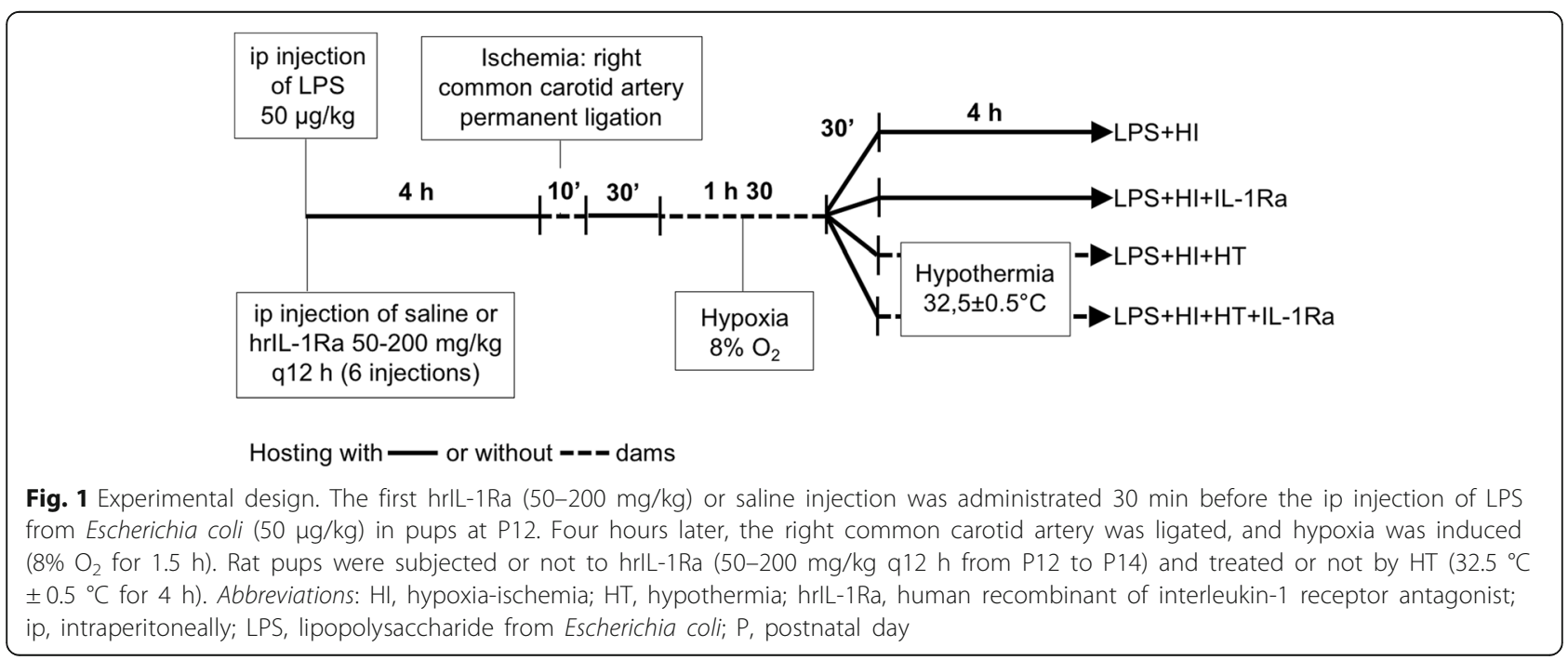


University (protocol \#2015-7691) in accordance with the Canadian Council on Animal Care guidelines: http:// www.ccac.ca/en_/standards/guidelines.

\section{Cerebrospinal fluid (CSF) collection}

CSF was collected by cisternal puncture of anesthetized rat pups at 4 or $24 \mathrm{~h}$ post-HI, as described $[18,19]$. The mean volume of CSF collected was $28 \mu \mathrm{l}$ (range 10$45 \mu \mathrm{l})$ with $96 \%$ of successful collection. CSF samples were kept frozen at $-80{ }^{\circ} \mathrm{C}$. Immediately after CSF collection, rat pups were euthanized by decapitation, and their forebrain rapidly removed and frozen by immersion in methylbutane on dry ice.

\section{Histology}

The brains were removed and fixed (paraformaldehyde $4 \%$, glutaraldehyde $0.1 \%$ ) at room temperature, paraffin-embedded, and cut in $5-\mu \mathrm{m}$ slices using a microtome, as described [9, 15]. Hematoxylin-eosin (H\&E) staining was performed to visualize brain injuries. Coronal sections were scanned, and the surface of the hemispheres were located at the epicenter of the infarct (Bregma from -2.30 to $-2.50 \mathrm{~mm}$ ), as previously described [9, 14, 15]. Core versus penumbra areas of brain infarcts were defined as previously described [9, 15]. Briefly, core injuries were associated with infarcted areas bearing cavitary lesions, whereas penumbra injuries were identified as regions surrounding the core where pycnotic neurons and/or loss of normal neuronal architecture were observed $[9,15]$.

\section{ELISA}

Protein extracts were prepared from right hemisphere forebrains as previously described [9, 14, 15]. ELISAs were performed on these protein extracts using

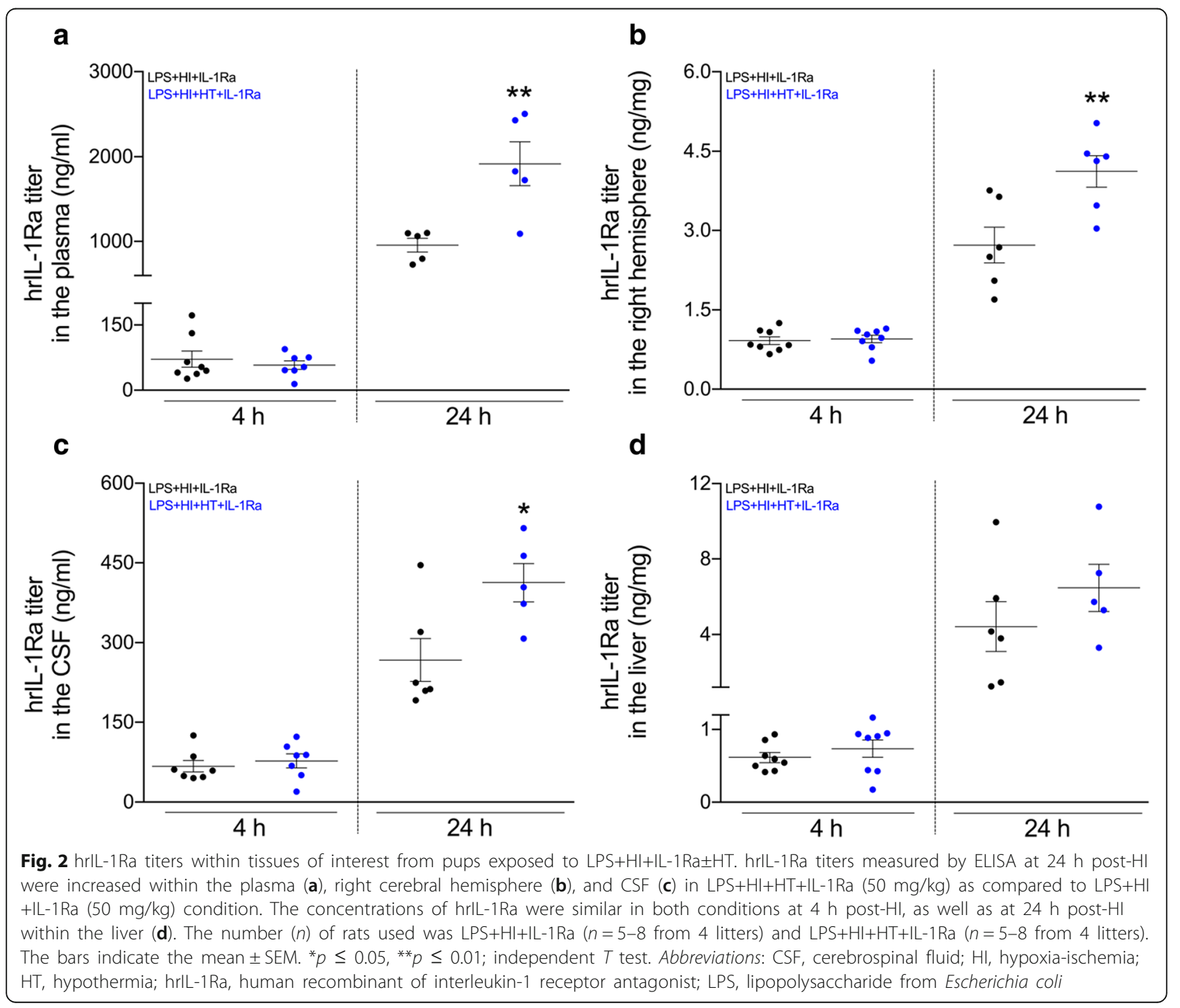


ELISA Kits (R\&D System, MN, USA), as previously described $[9,14,15]$.

\section{Behavioral test}

The open field test was used to determine spontaneous locomotor activity and exploratory behavior of juvenile rats (P20), as described previously [20]. The following parameters were assessed in the open field apparatus using Any-Maze Video Tracking System ${ }^{\text {mi }}$ (IL, USA) software: total distance traveled during the test period, mobile time, time in the center, and number of square visited.

\section{Data analysis}

Statistical analyses were performed using IBM Statistics 24 (SPSS) and GraphPad software version 6.02. The data are presented as the mean \pm standard error of the mean (SEM). Normality was assessed across experimental conditions. Data were analyzed by independent samples $t$ test or one-way analysis of variances (ANOVA) with Tukey's HSD test. Mann-Whitney $U$ test was used when data were not normally distributed. Male and female data were combined, because no significant interaction was observed between sex and treatment. The statistical significance level was set at $p \leq 0.05$.

\section{Results \\ Effect of HT on hrlL-1Ra titers within the tissues of interest}

At $4 \mathrm{~h}$ post-HI, HT did not modify the titer of hrIL-1Ra, at the dose of $50 \mathrm{mg} / \mathrm{kg}$, within the organ tested, namely plasma, liver, CSF, and right forebrain hemisphere exposed to LPS+HI (Fig. 2). At $24 \mathrm{~h}$ post-HI, HT induced a significant increase (50 to $65 \%$ ) of the hrIL-1Ra titers within the plasma, CSF, and right forebrain hemisphere exposed to LPS+HI (Fig. 2a-c).

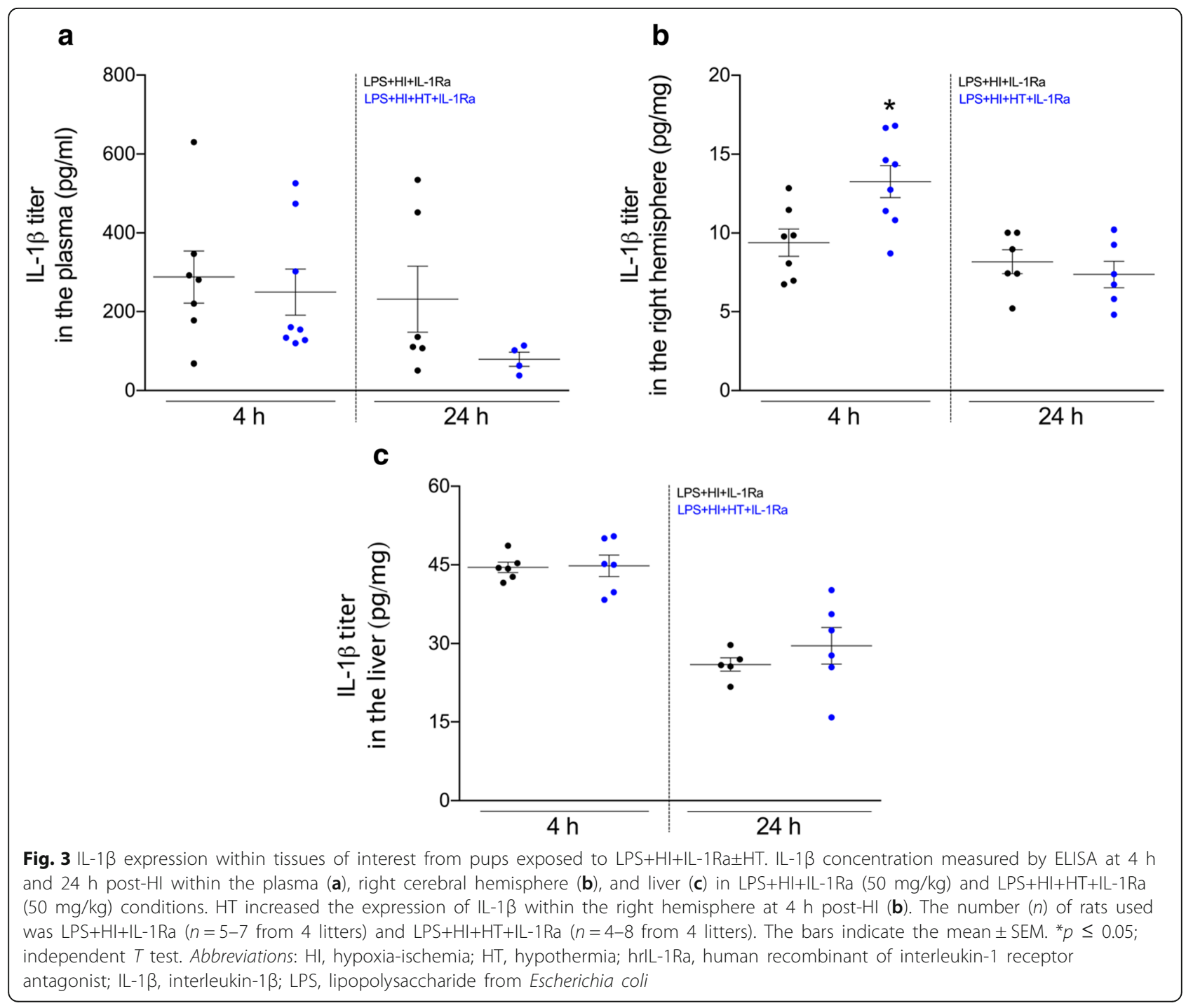




\section{Effect of HT+hrlL-1Ra $(50 \mathrm{mg} / \mathrm{kg})$ on the inflammatory cascade-induced by LPS+HI exposure}

IL-1Ra administration interferes with the autocrine loop of IL-1 $\beta$ synthesis and shuts down the downstream inflammatory cascades including TNF- $\alpha$ production [11, 15, 21, 22]. In HT conditions at 4 and $24 \mathrm{~h}$ post-HI, hrIL-1Ra $(50 \mathrm{mg} / \mathrm{kg})$ failed to counteract these pathways (Fig. 3), or conversely induced paradoxical upregulations of the IL-1 $\beta$ production at $4 \mathrm{~h}$ post-HI (Fig. $3 \mathrm{~b}$ ), and of the TNF- $\alpha$ production at $24 \mathrm{~h}$ post-HI in the LPS+HI-exposed right hemisphere (Fig. 4a).

\section{Dose-dependent neurotoxic effect of hrlL-1Ra added to HT}

HT alone exerted a neuroprotective effect on the extent of LPS+HI-induced core (Fig. 5a) and penumbral injuries (Fig. 5b-d). HT also protected against the loss of brain weight observed in such condition (Fig. 5e). hrIL-1Ra at the dose of $50 \mathrm{mg} / \mathrm{kg}$ did not provide any neuroprotective added value when combined to HT (Fig. 5a-d). hrIL-1Ra at the dose of $200 \mathrm{mg} / \mathrm{kg}$ increased LPS+HI-induced penumbral-but not core-injuries (Fig. 5b). Open field experiments in juvenile rats (P20) did not show any difference between $\mathrm{LPS}+\mathrm{HI}+\mathrm{HT}$ versus $\mathrm{LPS}+\mathrm{HI}+\mathrm{HT}$ +hrIL-1Ra (50 mg/kg) conditions (Fig. 6a-d).

\section{Discussion}

Our results showed that HT altered the pharmacodynamic parameters of hrIL-1Ra in our model of NE-induced by inflammation plus HI. HT increased the concentration of hrIL-1Ra (at $24 \mathrm{~h}$ post-HI) within the LPS+HI-exposed plasma, CSF, and forebrain. Paradoxically, this effect was not associated with an IL-1Ra-induced anti-inflammatory effect on the IL-1 system. We also observed a lack of effectiveness of the combination of hrIL-1Ra with HT, as compared to sole hrIL-1Ra in the same model of LPS $+\mathrm{HI}$-induced NE [14, 15].

According to the pharmacokinetic study performed in a rat model of arthritis [23], and also taking into account the short half-life (4-6 h) of IL-1Ra, it is unlikely that an accumulation of IL-1Ra would be due in our experimental design to the repeated administration of IL-1Ra every $12 \mathrm{~h}$. We hypothesize that the blood brain barrier (BBB) dysfunction induced by LPS+HI exposures might increase over time, with a more important BBB leak at $24 \mathrm{~h}$ (allowing the IL-1Ra to diffuse within the brain) as compared to $4 \mathrm{~h}$ post-HI. Few studies dealt with the impact of HT on the pharmacokinetic and pharmacodynamic of drugs used in the human neonatal context. However, it was shown that several drugs-e.g., isoflurane, morphine, ligands of $\beta 1$ and $\beta 2$ adrenoreceptors-had reduced metabolism and clearance on HT as compared to non-HT condition [5, 6]. Affinity between ligands and their cognate receptors as well as alterations of downstream signaling are also reported on HT $[5,6,8]$. Our results suggest that the bioaccumulation of hrIL-1Ra within the brain and CSF in LPS+HI+HT condition might result from a decreased clearance of hrIL-1Ra and/or from a decreased affinity of hrIL-1Ra for the IL-1R, and also possibly from the blockade of the IL-1R signaling pathway. hrIL-1Ra is rapidly eliminated (half-life of 4-6 h) mainly by the kidney through glomerular filtration (GFR) [24]. It is known in human studies that the GFR is decreased under hypothermic condition $[5,6]$.

\section{a}

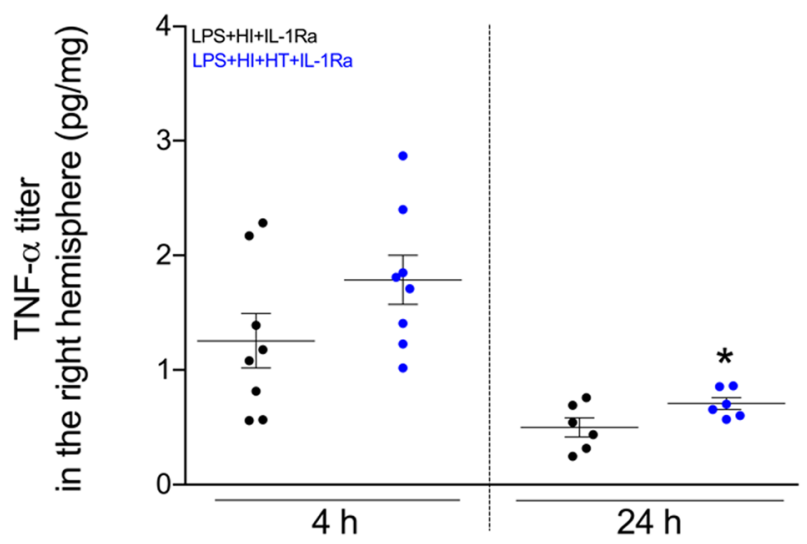

b

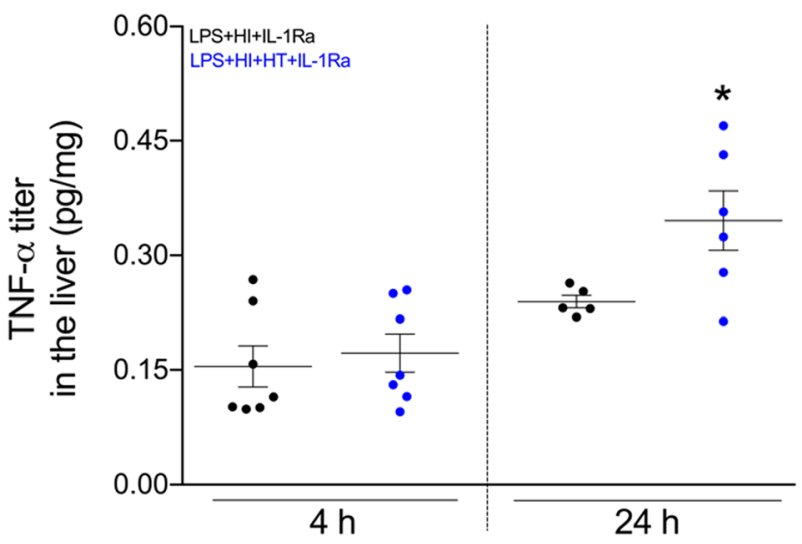

Fig. 4 TNF-a titers within tissues of interest from pups exposed to LPS+HI+IL-1Ra $\pm H T$. TNF-a concentrations measured by ELISA were increased at $24 \mathrm{~h}$ post-HI within the right cerebral hemisphere (a) and the liver (b) in LPS+HI+HT+IL-1Ra (50 mg/kg) as compared to LPS $+\mathrm{HI}+\mathrm{IL}-1 \mathrm{Ra}(50 \mathrm{mg} / \mathrm{kg})$ conditions. The TNF-a titers were similar in both conditions at $4 \mathrm{~h}$ post-HI. The number $(n)$ of rats used was LPS+HI +IL-1Ra ( $n=5-8$ from 4 litters) and LPS+HI+HT+IL-1Ra ( $n=6-8$ from 4 litters). The bars indicate the mean \pm SEM. ${ }^{*} p \leq 0.05$; independent $T$ test. Abbreviations: $\mathrm{HI}$, hypoxia-ischemia; HT, hypothermia; hrlL-1Ra, human recombinant of interleukin-1 receptor antagonist; LPS, lipopolysaccharide from Escherichia coli; TNF-a, tumor necrosis-a 


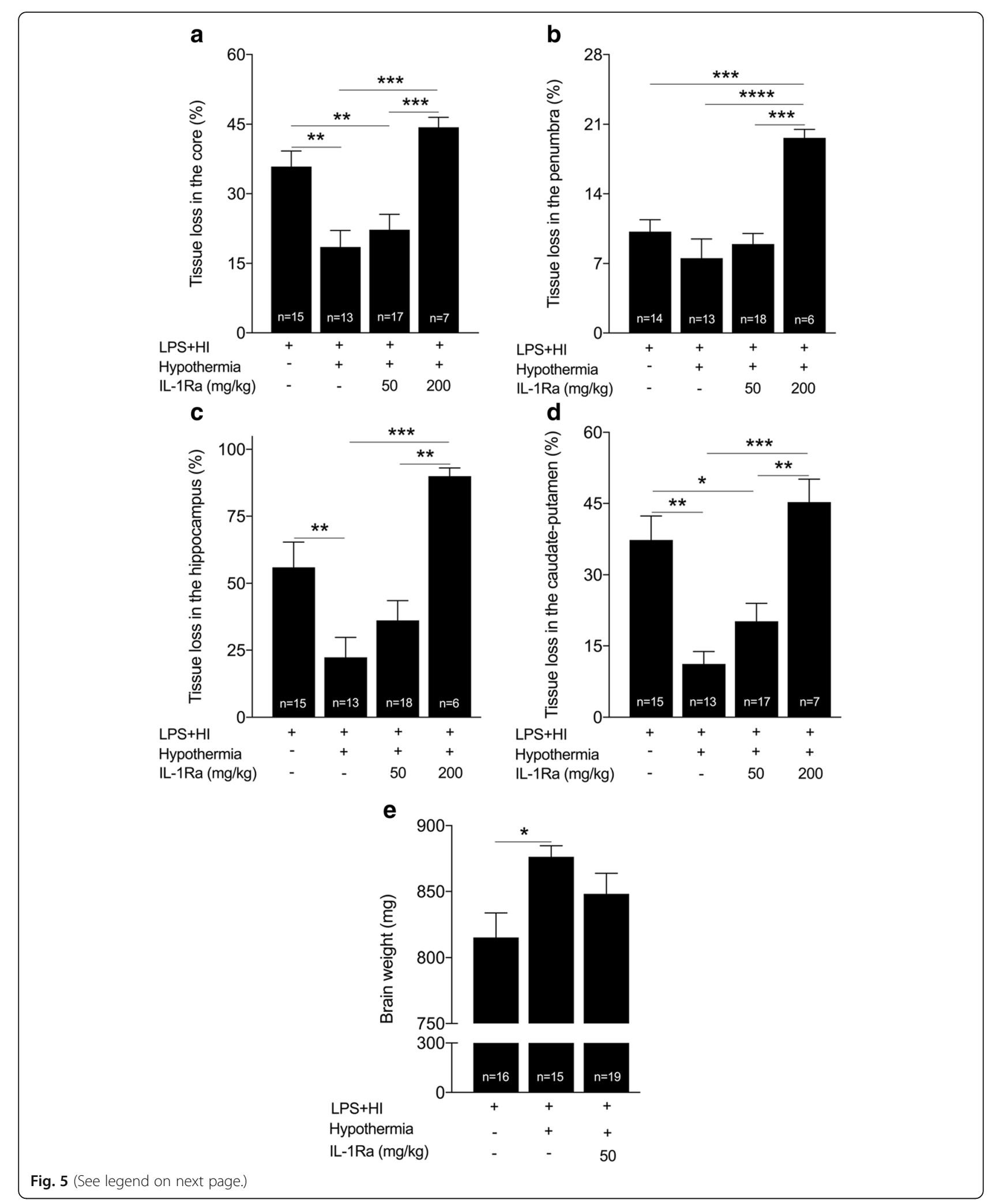


(See figure on previous page.)

Fig. 5 Comparison of the extent of brain injuries between LPS+HI $\pm H T \pm I L-1$ Ra conditions. Comparisons of the extent of core and penumbra injuries

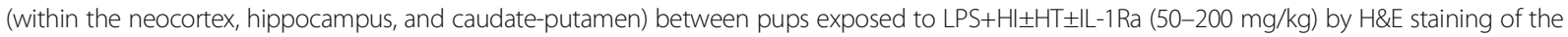
right forebrains at P20. HT reduced the surface of core and penumbra lesions (a-d), as well as alleviated the brain weight loss observed after LPS+HI exposure (e). The surface of core and penumbral lesions were similar in LPS+HI+HT+IL-1Ra (50 mg/kg) as compared to LPS+HI+HT condition (a-d). HT+hrlL-1Ra (200 mg/kg) increased the extent of penumbra injury as compared to the LPS+HI condition (b), as well as core and penumbral injuries as compared to LPS $+H+H+H T$ and LPS $+H I+H T+I L-1 R a(50 \mathrm{mg} / \mathrm{kg})(\mathbf{a}-\mathbf{d})$. The number $(n)$ of rats used was LPS $+H \mathrm{HI}(n=14-16$ from 9 litters), LPS $+H \mathrm{H}+\mathrm{HT}$ ( $n=13-15$ from 9 litters), LPS+HI+HT+IL-1Ra $50 \mathrm{mg} / \mathrm{kg}$ ( $n=17-19$ from 9 litters), and LPS+HI+HT+IL-1Ra $200 \mathrm{mg} / \mathrm{kg}$ ( $n=6-7$ from 3 litters). The bars indicate the mean \pm SEM. ${ }^{*} p \leq 0.05,{ }^{* *} p \leq 0.01,{ }^{* *} p \leq 0.001,{ }^{* * * *} p \leq 0.0001$; one-way ANOVA. Abbreviations: HI, hypoxia-ischemia; HT, hypothermia; hrlL-1Ra, human recombinant of interleukin-1 receptor antagonist; LPS, lipopolysaccharide from Escherichia coli

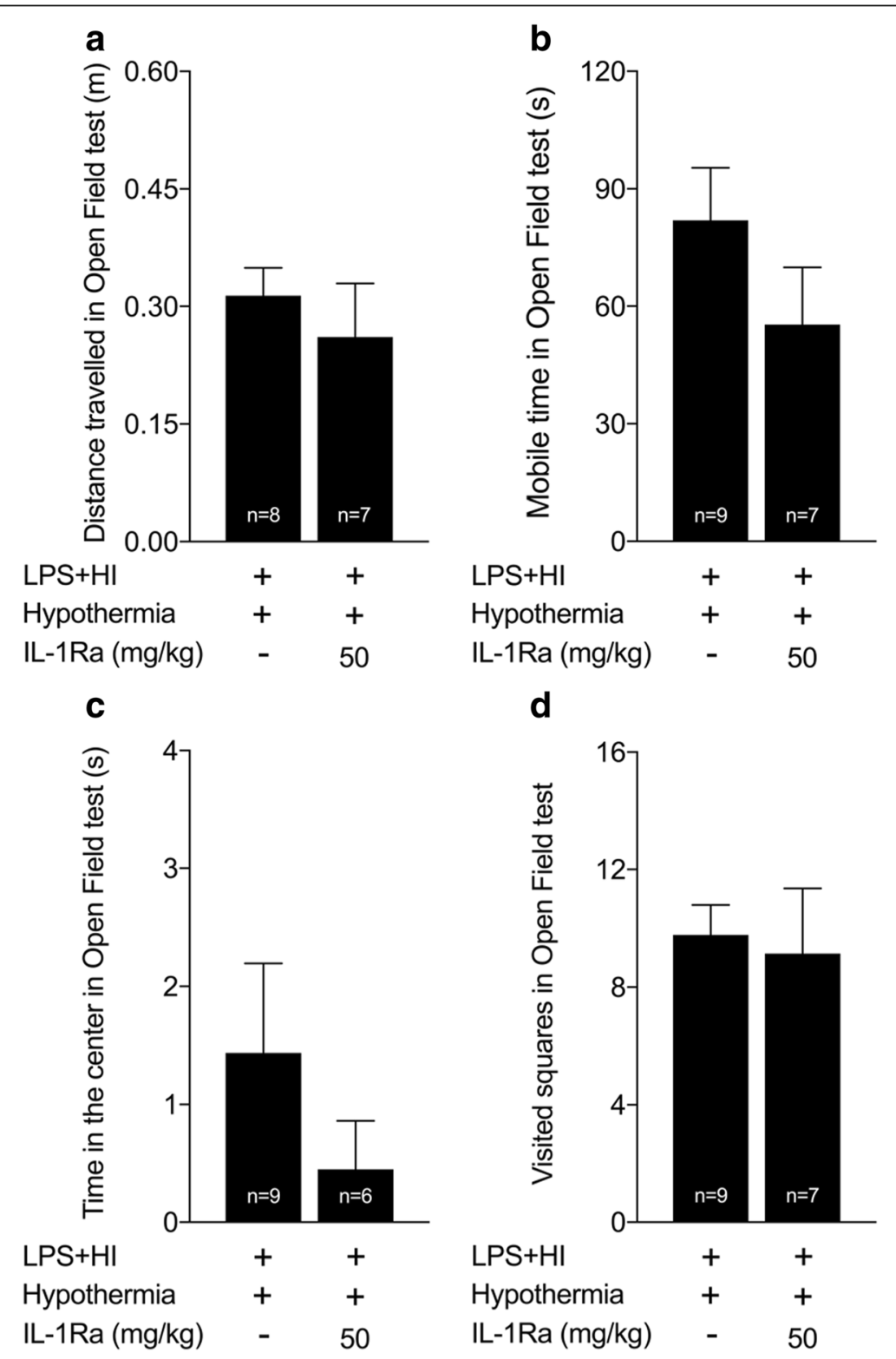

Fig. 6 Open field experiment at P20 in pups exposed to LPS+HI+HT \pm IL-1Ra (50 mg/kg). No difference was observed between the two conditions for the different open field parameters tested: the distance traveled (a), the mobile time $(\mathbf{b})$, the time in the center (c), and the visited squares in the apparatus (d). The number ( $n$ ) of rats used was LPS $+H+H T$ ( $n=8-9$ from 6 litters) and LPS+HI+HT+IL-1Ra $50 \mathrm{mg} / \mathrm{kg}$ ( $n=6-7$ from 5 litters). Independent $T$ test. Abbreviations: HI, hypoxia-ischemia; HT, hypothermia; hrlL-1 Ra, human recombinant of interleukin-1 receptor antagonist; LPS, lipopolysaccharide from Escherichia coli 
Besides, acute kidney injury can be associated to $\mathrm{HI}$ encephalopathy in the term neonate $[25,26]$. Hence, HI could potentially affect the renal filtration, especially in the HT condition, and decrease the clearance of IL-1Ra.

The increased hrIL-1Ra bioaccumulation in HT condition might explain the switch from protective [14, 15] to toxic effects of our highest dose of hrIL-1Ra $(200 \mathrm{mg} / \mathrm{kg} / 12 \mathrm{~h}$ for $72 \mathrm{~h})$. hrIL-1Ra $(200 \mathrm{mg} / \mathrm{kg} / 12 \mathrm{~h}$ for $72 \mathrm{~h}$ ) might reach in HT condition a toxic concentration within the brain inducing non-specific ligand-receptors interactions deleterious for neural cells.

This study has some limitations. The concentration of hrIL-1Ra was assessed only at 4 and $24 \mathrm{~h}$ post-HI. In future experiments, blood samples could be taken at additional time-points to study in more detail the pharmacology of this drug. However, to our knowledge, this is the first study focusing on the pharmacology of IL-1Ra in neonatal rats.

\section{Conclusion}

Our study addresses for the first time the impact of HT on hrIL-1Ra pharmacodynamics. HT might decrease the clearance of hIL-1Ra, inducing its bioaccumulation and loss of efficiency within the brain $[11,14,15,22,27]$. According to this hypothesis, current and future studies aiming to develop HT therapies-as already performed in neurological conditions, such as neonatal encephalopathy, stroke, traumatic brain injury, subarachnoid hemorrhage, spinal cord injury, and neurological outcomes of cardiac arrest [28-30]-should take into account the pharmacokinetic and pharmacodynamic impact of HT and the inherent modification of the safety profile of drugs.

\section{Abbreviations \\ TNF-a: Tumor necrosis factor a; CSF: Cerebrospinal fluid; GFR: Glomerular filtration; HI: Hypoxia-ischemia; hrlL-1Ra: Human recombinant of interleukin-1 receptor antagonist; HT: Hypothermia; IL: Interleukin; ip: Intraperitoneally; LPS: Lipopolysaccharide from Escherichia coli; NE: Neonatal encephalopathy; P: Postnatal day; SEM: Standard error of the mean}

\section{Acknowledgements}

We would like to thank Marie-Julie Allard for the statistical advice and Dr. Pia Wintermark for the helpful discussion. We would like to thank Noha Gerges for editing the manuscript.

\section{Funding}

This work was supported by grants from the Canadian Institute of Health Research, Foundation of Stars, Montreal Children Hospital Foundation (Hoppenheim Fund), and Heart and Stroke Foundation of Canada. This project has been made possible by Brain Canada Foundation through the Canada Brain Research Fund, with the financial support of Health Canada and the funding partners. The views expressed herein do not necessarily represent the views of the Minister of Health or the Government of Canada.

\section{Availability of data and materials}

The datasets used and/or analyzed during the current study are available from the corresponding author on reasonable request.

\section{Authors' contributions}

MC and CG carried out the experiments. MC performed the statistical analyses and drafted the manuscript. CG edited the manuscript. GS conceived the study, coordinated the project, and further edited the manuscript. All authors read and approved the final manuscript.

\section{Ethics approval}

Our research protocol was approved by the Ethics Committee from the Research Institute of the McGill University Health Center (\#2015-7691).

\section{Consent for publication}

Not applicable.

\section{Competing interests}

The authors declare that they have no competing interests.

\section{Publisher's Note}

Springer Nature remains neutral with regard to jurisdictional claims in published maps and institutional affiliations.

Received: 2 May 2018 Accepted: 17 July 2018

Published online: 30 July 2018

\section{References}

1. Colver A, Fairhurst C, Pharoah PO. Cerebral palsy. Lancet. 2014:383:1240-9. https://doi.org/10.1016/S0140-6736(13)61835-8.

2. Davidson JO, Wassink G, van den Heuij LG, Bennet L, Gunn AJ. Therapeutic hypothermia for neonatal hypoxic-ischemic encephalopathy - where to from here? Front Neurol. 2015;6:198. https://doi.org/10.3389/fneur.2015.00198.

3. Azzopardi D, Strohm B, Marlow N, Brocklehurst P, Deierl A, Eddama O, et al. Effects of hypothermia for perinatal asphyxia on childhood outcomes. N Engl J Med. 2014;371:140-9. https://doi.org/10.1056/NEJMoa1315788.

4. Hassell KJ, Ezzati M, Alonso-Alconada D, Hausenloy DJ, Robertson NJ. New horizons for newborn brain protection: enhancing endogenous neuroprotection. Arch Dis Child Fetal Neonatal Ed. 2015;100:F541-52. https://doi.org/10.1136/archdischild-2014-306284.

5. van den Broek MPH, Groenendaal F, Egberts ACG, Rademaker CMA. Effects of hypothermia on pharmacokinetics and pharmacodynamics: a systematic review of preclinical and clinical studies. Clin Pharmacokinet. 2010;49:277-94. https://doi.org/10.2165/11319360-000000000-00000.

6. Zhou J, Poloyac SM. The effect of therapeutic hypothermia on drug metabolism and response: cellular mechanisms to organ function. Expert Opin Drug Metab Toxicol. 2011;7:803-16. https://doi.org/10.1517/17425255. 2011.574127.

7. de Haan TR, Bijleveld YA, van der Lee JH, Groenendaal F, van den Broek MPH, Rademaker CMA, et al. Pharmacokinetics and pharmacodynamics of medication in asphyxiated newborns during controlled hypothermia. The PharmaCool multicenter study. BMC Pediatr. 2012;12:45. https://doi.org/10. 1186/1471-2431-12-45.

8. Ezzati M, Kawano G, Rocha-Ferreira E, Alonso-Alconada D, Hassell JK, Broad $K D$, et al. Dexmedetomidine combined with therapeutic hypothermia is associated with cardiovascular instability and neurotoxicity in a piglet model of perinatal asphyxia. Dev Neurosci. 2017;39:156-70. https://doi.org/ $10.1159 / 000458438$

9. Chevin M, Guiraut C, Maurice-Gelinas C, Deslauriers J, Grignon S, Sébire G. Neuroprotective effects of hypothermia in inflammatory-sensitized hypoxicischemic encephalopathy. Int J Dev Neurosci. 2016;55:1-8. https://doi.org/ 10.1016/j.ijdevneu.2016.09.002

10. Rocha-Ferreira E, Kelen D, Faulkner S, Broad KD, Chandrasekaran M, Kerenyi Á, et al. Systemic pro-inflammatory cytokine status following therapeutic hypothermia in a piglet hypoxia-ischemia model. J Neuroinflammation. 2017;14:44. https://doi.org/10.1186/s12974-017-0821-x.

11. Leitner K, Al Shammary M, McLane M, Johnston MV, Elovitz MA, Burd I. IL-1 receptor blockade prevents fetal cortical brain injury but not preterm birth in a mouse model of inflammation-induced preterm birth and perinatal brain injury. Am J Reprod Immunol. 2014;71:418-26. https://doi.org/10.1111/ aji.12216.

12. Rosenzweig JM, Lei J, Burd I. Interleukin-1 receptor blockade in perinatal brain injury. Front Pediatr. 2014;2:108. https://doi.org/10.3389/fped.2014. 00108. 
13. Medel-Matus J-S, Álvarez-Croda D-M, Martínez-Quiroz J, Beltrán-Parrazal L, Morgado-Valle C, López-Meraz M-L. IL-1 $\beta$ increases necrotic neuronal cell death in the developing rat hippocampus after status epilepticus by activating type I IL-1 receptor (IL-1RI). Int I Dev Neurosci. 2014;38:232-40. https://doi.org/10.1016/j.ijdevneu.2014.09.006.

14. Savard A, Lavoie K, Brochu M-E, Grbic D, Lepage M, Gris D, et al. Involvement of neuronal IL-1 $\beta$ in acquired brain lesions in a rat model of neonatal encephalopathy. J Neuroinflammation. 2013;10:110. https://doi. org/10.1186/1742-2094-10-110

15. Savard A, Brochu M-E, Chevin M, Guiraut C, Grbic D, Sébire G. Neuronal selfinjury mediated by IL-1 $\beta$ and MMP-9 in a cerebral palsy model of severe neonatal encephalopathy induced by immune activation plus hypoxiaischemia. J Neuroinflammation. 2015;12:111. https://doi.org/10.1186/s12974015-0330-8.

16. Berry CA, Nitsos I, Hillman NH, Pillow JJ, Polglase GR, Kramer BW, et al. Interleukin-1 in lipopolysaccharide induced chorioamnionitis in the fetal sheep. Reprod Sci. 2011;18:1092-102. https://doi.org/10.1177/1933719111404609.

17. Brochu M-E, Girard S, Lavoie K, Sébire G. Developmental regulation of the neuroinflammatory responses to LPS and/or hypoxia-ischemia between preterm and term neonates: an experimental study. J Neuroinflammation. 2011;8:55. https://doi.org/10.1186/1742-2094-8-55.

18. Mahat MYA, Fakrudeen Ali Ahamed N, Chandrasekaran S, Rajagopal S, Narayanan S, Surendran N. An improved method of transcutaneous cisterna magna puncture for cerebrospinal fluid sampling in rats. J Neurosci Methods. 2012;211:272-9. https://doi.org/10.1016/j.jneumeth.2012.09.013.

19. Consiglio AR, Lucion AB. Technique for collecting cerebrospinal fluid in the cisterna magna of non-anesthetized rats. Brain Res Protocol. 2000;5:109-14. https://doi.org/10.1016/S1385-299X(99)00062-8.

20. Girard S, Kadhim H, Beaudet N, Sarret P, Sébire G. Developmental motor deficits induced by combined fetal exposure to lipopolysaccharide and early neonatal hypoxia/ischemia: a novel animal model for cerebral palsy in very premature infants. Neuroscience. 2009;158:673-82. https://doi.org/10. 1016/j.neuroscience.2008.10.032.

21. Girard S, Sébire H, Brochu M-E, Briota S, Sarret P, Sébire G. Postnatal administration of IL-1Ra exerts neuroprotective effects following perinatal inflammation and/or hypoxic-ischemic injuries. Brain Behav Immun. 2012;26: 1331-9. https://doi.org/10.1016/j.bbi.2012.09.001.

22. Lan K-M, Tien L-T, Pang Y, Bhatt AJ, Fan L-W. IL-1 receptor antagonist attenuates neonatal lipopolysaccharide-induced long-lasting learning impairment and hippocampal injury in adult rats. Toxicol Lett. 2015;234:30-9. https://doi.org/10. 1016/j.toxlet.2015.02.002.

23. Zuurmond A-M, Koudijs A, van El B, Doornbos RP, van Manen-Vernooij BCT, Bastiaans JHMW, et al. Integration of efficacy, pharmacokinetic and safety assessment of interleukin-1 receptor antagonist in a preclinical model of arthritis. Regul Toxicol Pharmacol. 2011;59:461-70. https://doi.org/10.1016/j. yrtph.2011.01.014

24. Liu D, Lon H-K, Dubois DC, Almon RR, Jusko WJ. Population pharmacokinetic-pharmacodynamic-disease progression model for effects of anakinra in Lewis rats with collagen-induced arthritis. J Pharmacokinet Pharmacodyn. 2011;38:769-86. https://doi.org/10.1007/s10928-011-9219-z.

25. Durkan AM, Alexander RT. Acute kidney injury post neonatal asphyxia. J Pediatr. 2011;158(2 Suppl):e29-33. https://doi.org/10.1016/j.jpeds.2010. 11.010

26. Sweetman DU, Riordan M, Molloy EJ. Management of renal dysfunction following term perinatal hypoxia-ischaemia. Acta Paediatr. 2013;102:233-41. https://doi.org/10.1111/apa.12116

27. Pang Y, Tien L-T, Zhu H, Shen J, Wright CF, Jones TK, et al. Interleukin-1 receptor antagonist reduces neonatal lipopolysaccharide-induced longlasting neurobehavioral deficits and dopaminergic neuronal injury in adult rats. Int J Mol Sci. 2015;16:8635-54. https://doi.org/10.3390/ijms16048635.

28. Han Z, Liu X, Luo Y, Ji X. Therapeutic hypothermia for stroke: where to go? Exp Neurol. 2015;272:67-77. https://doi.org/10.1016/j.expneurol.2015.06.006.

29. Karnatovskaia LV, Wartenberg KE, Freeman WD. Therapeutic hypothermia for neuroprotection: history, mechanisms, risks, and clinical applications. Neurohospitalist. 2014;4:153-63. https://doi.org/10.1177/1941874413519802.

30. Zhang XW, Xie JF, Chen JX, Huang YZ, Guo FM, Yang Y, et al. The effect of mild induced hypothermia on outcomes of patients after cardiac arrest: a systematic review and meta-analysis of randomised controlled trials. Crit Care. 2015;19:417. https://doi.org/10.1186/s13054-015-1133-0.

Ready to submit your research? Choose BMC and benefit from:

- fast, convenient online submission

- thorough peer review by experienced researchers in your field

- rapid publication on acceptance

- support for research data, including large and complex data types

- gold Open Access which fosters wider collaboration and increased citations

- maximum visibility for your research: over $100 \mathrm{M}$ website views per year

At BMC, research is always in progress.

Learn more biomedcentral.com/submissions 